\title{
Body mass, body composition and sleeping metabolic rate before, during and after endurance training
}

Citation for published version (APA):

Westerterp, K. R., Meijer, G. A. L., Schoffelen, P. F. M., \& Janssen, E. M. (1994). Body mass, body composition and sleeping metabolic rate before, during and after endurance training. European Journal of Applied Physiology, 69(3), 203-208. https://doi.org/10.1007/BF01094789

Document status and date:

Published: 01/01/1994

DOI:

10.1007/BF01094789

Document Version:

Publisher's PDF, also known as Version of record

Document license:

Taverne

Please check the document version of this publication:

- A submitted manuscript is the version of the article upon submission and before peer-review. There can be important differences between the submitted version and the official published version of record.

People interested in the research are advised to contact the author for the final version of the publication, or visit the DOI to the publisher's website.

- The final author version and the galley proof are versions of the publication after peer review.

- The final published version features the final layout of the paper including the volume, issue and page numbers.

Link to publication

\footnotetext{
General rights rights.

- You may freely distribute the URL identifying the publication in the public portal. please follow below link for the End User Agreement:

www.umlib.nl/taverne-license

Take down policy

If you believe that this document breaches copyright please contact us at:

repository@maastrichtuniversity.nl

providing details and we will investigate your claim.
}

Copyright and moral rights for the publications made accessible in the public portal are retained by the authors and/or other copyright owners and it is a condition of accessing publications that users recognise and abide by the legal requirements associated with these

- Users may download and print one copy of any publication from the public portal for the purpose of private study or research.

- You may not further distribute the material or use it for any profit-making activity or commercial gain

If the publication is distributed under the terms of Article $25 \mathrm{fa}$ of the Dutch Copyright Act, indicated by the "Taverne" license above, 
Eur J Appl Physiol (1994) 69:203-208

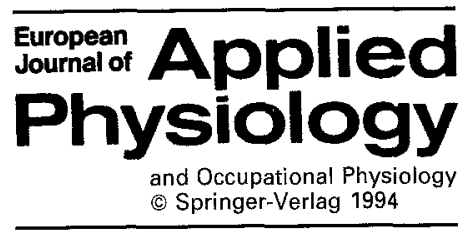

\title{
Body mass, body composition and sleeping metabolic rate before, during and after endurance training
}

\author{
Klaas R. Westerterp, Gerwin A. L. Meijer, Paul Schoffelen, Eugene M. E. Janssen \\ Department of Human Biology, University of Limburg, P.O. Box 616, NL-6200 MD Maastricht, The Netherlands
}

Accepted: 7 April 1994

\begin{abstract}
Metabolic rate, more specifically resting metabolic rate (RMR) or sleeping metabolic rate (SMR), of an adult subject is usually expressed as a function of the fat-free mass (FFM). Chronic exercise is thought to increase FFM and thus to increase RMR and SMR. We determined body mass (BM), body composition, and SMR before, during, and after an endurance training programme without interfering with energy intake. The subjects were 11 women and 12 men, aged 37 (SD 3) years and body mass index $22.3(\mathrm{SD} 1.5) \mathrm{kg} \cdot \mathrm{m}^{-2}$. The endurance training prepared subjects to run a half marathon competition after 44 weeks. The SMR was measured overnight in a respiration chamber. Body composition was measured by hydrostatic weighing. Measurements were performed at 0, 8, 20, 40, and 90 weeks after the start of the training. The BM had decreased from a mean value of 66.6 (SD 6.9) to 65.6 (SD $6.7) \mathrm{kg}(P<0.01)$, fat mass $(\mathrm{FM})$ had decreased from 17.1 (SD 3.9) to 13.5 (SD 3.6) $\mathrm{kg}(P<0.001$ ), and FFM had increased from 49.5 (SD 7.3) to 52.2 (SD 7.6) kg $(P<0.001)$ at 40 weeks. Mean SMR before and after 40 weeks training was 6.5 (SD 0.7) and 6.2 (SD 0.6) $\mathrm{MJ} \cdot \mathrm{day}^{-1}(P<0.05)$. The decrease in SMR was related to the decrease in BM $(r=0.62, P=0.001)$. At 90 weeks, when most subjects had not trained for nearly a year, BM and SMR were not significantly different from the initial value while FM and FFM had not changed since week 40 of training. In conclusion, it was found that an exercise induced increase in FFM did not result in an increase in SMR. There was an indication of the opposite effect, a decrease in SMR in the long term during training, possibly as a defence mechanism of the body in the maintenance of BM.
\end{abstract}

Key words: Body mass regulation - Fat free mass - Fat mass - Substrate utilization

\section{Introduction}

Daily energy expenditure consists of three components, resting metabolic rate (RMR), diet induced thermogenesis and activity induced energy expenditure. The RMR is the energy expenditure necessary to maintain the physiological processes during rest in the postabsorptive state. For the majority of people, RMR comprises the largest component of average daily metabolic rate. Diet induced thermogenesis has been found to be on average $10 \%$ of metabolizable energy intake (Schutz et al. 1984). Activity induced energy expenditure is more variable and ranges between $20 \%$ and $40 \%$ of average daily metabolic rate for sedentary and highly active people, respectively. Physical activity not only influences activity induced energy expenditure but may affect RMR as well. The present study focused on the relationship between physical activity and RMR.

In the long term, exercise training may result in an increase of the muscle mass, the largest component of the fat-free mass (FFM) of the body. The FFM has been shown to be the main determinant of RMR (Garby et al. 1988) and thus a chronic effect of exercise training on RMR could firstly be explained by a change in body composition. Secondly, as reviewed by Poehlman and Horton (1989), trained individuals often show a higher RMR after correction for differences in FFM. Examples are found in studies of Tremblay et al. $(1985,1986)$ who have shown RMR to be higher in athletes than in nontrained individuals and in a study of Goran and Poehlman (1992) showing an increase in RMR after an 8-week endurance training programme in elderly subjects. As reviewed by Poehlman et al. (1989), possible mechanisms are an increased resting stroke volume, increased number and size of muscle mitochondria, increased protein metabolism, and an increased level of glucose storage. Other studies, e.g. of Meredith et al. (1989), have failed to show a training induced increase in RMR. Thus the magnitude and direction of a relationship between chronic exercise and RMR is still unclear (Poehlman et al. 1989). 
The effect of physical activity on RMR is of major importance for body mass (BM) regulation. Usually, physical activity itself does not last for long time intervals and therefore, an effect on average daily metabolic rate through RMR could be equivalent to the direct activity induced increase in energy expenditure. Effects of exercise on RMR are twofold, an acute effect, within $24 \mathrm{~h}$, and a chronic effect measured in the long term. The acute effect is an increase in RMR directly after the exercise has finished, which has been called excess postexercise oxygen consumption or EPOC (Gaesser and Brooks 1984). In a recent review, Poehlman and Horton (1989) have questioned the effect of EPOC on average daily metabolic rate. The chronic effect was measured after nonexercise days as well. Here, we focused on the chronic effect of physical activity, i.e. exercise training, on the resting component of average daily metabolic rate.

The reasons for the lack of agreement on the relationship between chronic exercise and RMR are probably methodological. Most studies have been cross-sectional, comparing athletes with sedentary control subjects. Substantial variance in RMR has existed among individuals due to genetic factors (Bogardus et al. 1986). These genetic factors might also be important for the chances to become an athlete. Longitudinal studies, comparing RMR before and after participation in an exercise training programme, have varied with respect to control of the exercise level before training, training load, and length of the training programme. In addition, most longitudinal studies concerning the effects of chronic exercise on RMR have focused on the combination of exercise and diet. Exercise has been induced in these programmes as an attempt to reverse the dietary depression of RMR. However, in these studies also, no effects of chronic exercise on RMR have been found (Horton 1985; Saris 1991).

The purpose of the present study was to measure the effect of chronic exercise on RMR and resting substrate utilization in a longitudinal long-term intervention. Sedentary subjects were trained to run a half-marathon competition after 44 weeks. During this period, observations were made on four occasions $(0,8,20$ and 40 weeks). Finally, one observation was made 1 year after finishing the training programme ( 90 weeks). Data from this study on energy balance and body composition over the first 40 weeks have been reported earlier (Meijer et al. 1991a, b; Westerterp et al. 1992a).

\section{Methods}

Subjects. The subjects were recruited through the local media. Out of 370 respondents, 16 women and 16 men were selected who had had a minimal participation in sports (less than $1 \mathrm{~h}$ per week), within the age range of 28-41 years, and having a body mass index between 19.4 and $26.4 \mathrm{~kg} \cdot \mathrm{m}^{-2}$ (Table 1). The subjects were medically examined and gave their written informed consent before participation.

Procedure. The training programme aimed at running a half-marathon competition after 44 weeks. In between, the subjects ran a
Table 1. Characteristics of male and female subjects, both in sequence of ascending percentage body fat as determined with hydrostatic weighing

\begin{tabular}{|c|c|c|c|c|c|c|}
\hline & $\begin{array}{l}\text { Age } \\
\text { (years) }\end{array}$ & Height & Body mass & Body fat & (1) & (2) \\
\hline \multicolumn{7}{|c|}{ Men } \\
\hline 1 & 33 & 1.73 & 63.2 & 15.1 & & \\
\hline 2 & 34 & 1.88 & 75.6 & 15.1 & $*$ & \\
\hline 3 & 40 & 1.76 & 69.7 & 18.1 & $* *$ & \\
\hline 4 & 39 & 1.75 & 59.4 & 19.4 & $*$ & \\
\hline 5 & 32 & 1.86 & 79.6 & 19.9 & & \\
\hline 6 & 40 & 1.79 & 66.3 & 20.2 & & \\
\hline 7 & 35 & 1.80 & 72.0 & 21.8 & $*$ & \\
\hline 8 & 40 & 1.80 & 75.7 & 24.1 & & \\
\hline 9 & 33 & 1.79 & 69.4 & 24.7 & $* *$ & \\
\hline 10 & 39 & 1.85 & 74.2 & 25.4 & $* *$ & $\bullet$ \\
\hline 11 & 39 & 1.80 & 79.5 & 26.4 & & \\
\hline 12 & 40 & 1.73 & 77.0 & 26.5 & $* *$ & $\bullet$ \\
\hline 13 & 36 & 1.78 & 77.3 & 26.8 & & $\bullet$ \\
\hline 14 & 37 & 1.69 & 70.3 & 26.8 & * & \\
\hline 15 & 35 & 1.80 & 79.3 & 30.5 & & \\
\hline 16 & 41 & 1.73 & 68.0 & 31.5 & & \\
\hline \multicolumn{7}{|c|}{ Women } \\
\hline 1 & 35 & 1.72 & 63.3 & 24.8 & & \\
\hline 2 & 32 & 1.63 & 54.0 & 25.5 & & \\
\hline 3 & 41 & 1.65 & 64.4 & 27.0 & $*$ & \\
\hline 4 & 32 & 1.57 & 52.6 & 27.7 & $* *$ & \\
\hline 5 & 36 & 1.76 & 66.8 & 28.1 & & \\
\hline 6 & 35 & 1.67 & 60.1 & 29.6 & & \\
\hline 7 & 32 & 1.81 & 70.4 & 30.6 & $*$ & \\
\hline 8 & 38 & 1.73 & 68.5 & 32.6 & $* *$ & \\
\hline 9 & 38 & 1.65 & 61.0 & 33.2 & & \\
\hline 10 & 41 & 1.68 & 65.8 & 35.0 & $* *$ & \\
\hline 11 & 40 & 1.79 & 83.3 & 35.6 & & \\
\hline 12 & 32 & 1.58 & 61.1 & 36.0 & & $\bullet$ \\
\hline 13 & 28 & 1.68 & 68.8 & 37.0 & & \\
\hline 14 & 35 & 1.67 & 73.7 & 38.4 & $* *$ & : \\
\hline 15 & 31 & 1.64 & 65.6 & 43.3 & $*$ & $:$ \\
\hline 16 & 39 & 1.68 & 74.6 & 45.4 & $*$ & 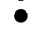 \\
\hline
\end{tabular}

(1) *** Subjects participating in energy expenditure measurements with doubly labelled water in week 0 and 8 , and in week 0 , 8,20 and 40 , respectively

(2) $\bullet$ Subjects withdrawn from the study

$10-\mathrm{km}$ and $15-\mathrm{km}$ race after 10 and 24 weeks, respectively. The training, supervised by one of the authors (GMEJ), consisted of four training sessions per week, increasing running time gradually from $10-30 \mathrm{~min}$ to $30-90 \mathrm{~min}$ per training session as described elsewhere (Janssen and ten Hoor 1989; Meijer et al. 1991a). The training distance increased from 0 to $25 \mathrm{~km} \cdot$ week $^{-1}$ after 8 weeks training and subsequently doubled to $50 \mathrm{~km} \cdot$ week $^{-1}$ after 40 weeks training. Before and directly after the training programme, maximal power output of the subjects was measured during a stepwise progressive cycling test until exhaustion using an electromagnetically braked cycle ergometer (Jaeger ER 800) and an automated system for measurement of oxygen uptake (EOS-sprint). The test programme started with a warming up for $4 \mathrm{~min}$ at $100 \mathrm{~W}$, followed by a stepwise increasing intensity of $50 \mathrm{~W}$ every $3 \mathrm{~min}$. If the heart rate exceeded 160 beats $\cdot \mathrm{min}^{-1}$, the size of the intensity increment was reduced to $25 \mathrm{~W}$.

During the study 5 women and 4 men withdrew, not being able to keep up with the training programme. Of the total, 11 women and 12 men actually finished the half-marathon competition after 44 weeks of preparation. All the subjects who withdrew had an initial percentage body fat above the group mean for their sex (Table 1). Below, we only show the results from the remain- 
ing 23 subjects to allow comparisons in time over all five observation intervals. There were 4 subjects, 1 women and 3 men, who continued training at the same intensity after they had run the half marathon until the final measurements at 90 weeks. Amongst the others, 6 women and 1 man continued training at a reduced intensity while the remaining subjects, 4 women and 8 men, ceased training altogether.

Observations included energy intake, average daily metabolic rate, sleeping metabolic rate (SMR), fuel utilization as measured by respiratory exchange ratio $(R)$ and body composition at four time intervals: before the start of the training $(0)$ and 8,20 , and 40 weeks after the start of the training programme. In addition, body composition, SMR and fuel utilization were measured at 90 weeks, 1 year after the training programme had finished. Energy intake was measured using a 7-day dietary record. In 16 subjects (see Table 1) average daily energy expenditure was measured simultaneously using doubly labelled water. Here we focused on SMR and body composition. Methods and results for energy intake and average daily metabolic rate have been described earlier (Westerterp et al. 1992a) and will be mentioned as appropriate. The SMR was observed during an overnight stay in a respiration chamber as described earlier (Schoffelen et al. 1984). The subjects entered the respiration chamber at 1830 hours after a day during which they had refrained from training and after they had had their last meal of the day at home. In the chamber no food was consumed but coffee or tea were allowed until 2200 hours. The SMR was measured over a 3-h interval between 0100 and 0700 hours with the minimal activity level judged from Doppler radar observation. The system was checked monthly with ethanol combustion. Differences between calculated and measured $\mathrm{O}_{2}$ consumption and $\mathrm{CO}_{2}$ production were 0.5 (SD 1.2) and -2.5 (SD 1.6$) \%$, respectively. Body composition was measured by hydrodensitometry, directly after subjects left the respiration chamber, between 0730 and 0900 hours. Their BM was measured with a digital balance (Mettler, 240C). Body volume was measured under water using the same balance type and simultaneous measurement of lung volume were carried out (He-dilution, Mijnhardt Volugraph). Differences between repeated measurements in 13 individuals within 7 days were 0.02 (SD 0.20) 1 . Fat mass (FM) and FFM were calculated from mass and volume using the Siri equation (1956).

Statistics. Differences between times of measurement (e.g. before vs after 40 weeks training) were analysed by repeated measures analysis of variance (ANOVA) and paired Student's $t$-tests. Relationships between variables were assessed with correlation tests (Pearson $r$ ). Finally, the change in SMR was analysed as a function of changes in FFM and FM using multiple regression analysis.

\section{Results}

The initial physical activity level [(average daily metabolic rate) $\cdot \mathrm{SMR}^{-1}$, as measured in 5 women and 8 men using doubly labelled water (average daily metabolic rate) and a respiration chamber (SMR), was 1.63 (SD 0.19) (Westerterp et al. 1992a), close to that for light activity (World Health Organisation 1985). Average daily metabolic rate in these subjects increased from 11.1 (SD 1.9) $\mathrm{MJ} \cdot$ day $^{-1}$ at the start to 13.5 (SD 1.9) $\mathrm{MJ} \cdot$ day $^{-1}$ at 40 weeks, a mean increase of 22 (SD 10 ) $\%$ ranging from $+5 \%$ to $+37 \%$. For the whole group, the maximal power output, as measured on a cycle ergometer, increased from 163 (SD 15) to 191 (SD 17) W (women, $P<0.01$ ) and from 227 (SD 36) to 259 (SD 35) W (men, $P<0.01$ ) from before until 40 weeks after the start of the training. The heart rate at maximal power output decreased from 186 (SD 7) to 179 (SD 9) beats $\cdot \mathrm{min}^{-1}(P<0.05)$ for the women and from 186 (SD 10) to 182 (SD 10) beats $\cdot \mathrm{min}^{-1}$ (ns) for the men. For both effects there was no interaction between the sexes $[F(1,21)=0.3, \quad P=0.88$, and $F(1,21)=0.41, P=0.53$, respectively].

The BM did not show much change (Table 2). In the women changes from the initial value were not significant. The men showed an average BM loss of $1.3 \mathrm{~kg}$ at 40 weeks $(P<0.01)$. Overall, BM initially showed an increase, subsequently decreased during the training programme, and had returned to a value not significantly different from the initial value at 1 year after the training programme. However, changes in body composition were more pronounced. There was an almost linear decrease in FM and a corresponding increase in FFM during the training programme in both sexes (Table 2). The women lost on average 2.8 (SD 0.5) $\mathrm{kg} \mathrm{FM}$ $(P<0.01)$ and gained 2.1 (SD 0.4) kg FFM $(P<0.01)$, from the start until interval 4,40 weeks afterwards. In the men, the changes over the corresponding interval were minus 4.5 (SD 0.6) $\mathrm{kg} \mathrm{FM}(P<0.01)$ and plus 3.2 $(S D 0.5) \mathrm{kg}$ FFM $(P<0.01)$. At 1 year after the training programme, both sexes had partly regained the FM lost while the gain in FFM had been maintained.

Table 2. Body mass, fat mass, and fat-free mass before $(0)$ and $8,20,40$, and 90 weeks after the start of the training period

\begin{tabular}{|c|c|c|c|c|c|c|c|c|c|c|c|c|c|c|c|}
\hline \multirow[b]{2}{*}{ Weeks } & \multicolumn{5}{|c|}{$\begin{array}{l}\text { Body mass } \\
\text { (kg) }\end{array}$} & \multicolumn{5}{|c|}{$\begin{array}{l}\text { Fat mass } \\
(\mathrm{kg})\end{array}$} & \multicolumn{5}{|c|}{$\begin{array}{l}\text { Fat-free mass } \\
(\mathrm{kg})\end{array}$} \\
\hline & 0 & 8 & 20 & 40 & 90 & 0 & 8 & 20 & 40 & 90 & 0 & 8 & 20 & 40 & 90 \\
\hline \multicolumn{16}{|c|}{ Women $(n=11)$} \\
\hline Mean & 62.5 & 63.2 & 62.5 & 61.8 & 63.8 & 18.8 & 18.3 & $17.9^{\mathrm{a}}$ & $16.0^{\mathrm{b}}$ & 17.2 & 43.7 & $44.9^{\mathrm{b}}$ & $44.6^{\mathrm{a}}$ & $45.8^{\mathrm{b}}$ & $46.6^{b}$ \\
\hline $\mathrm{SD}$ & 5.6 & 5.2 & 5.3 & 5.3 & 6.9 & 3.3 & 2.8 & 3.0 & 3.0 & 4.4 & 3.9 & 4.4 & 4.5 & 4.0 & 3.7 \\
\hline \multicolumn{16}{|c|}{$\operatorname{Men}(n=12)$} \\
\hline Mean & 70.4 & 70.9 & 70.0 & $69.1^{\mathrm{b}}$ & 70.7 & 15.6 & 14.8 & $12.9^{\mathrm{b}}$ & $11.1^{\mathrm{b}}$ & $12.3^{\mathrm{b}}$ & 54.8 & 56.1 & $57.1^{b}$ & $58.0^{\mathrm{b}}$ & $58.4^{\mathrm{b}}$ \\
\hline $\mathrm{SD}$ & 5.8 & 5.9 & 5.7 & 5.9 & 5.9 & 3.9 & 2.9 & 2.1 & 2.3 & 2.3 & 5.4 & 5.8 & 5.7 & 4.8 & 5.0 \\
\hline \multicolumn{16}{|c|}{ Total $(n=23)$} \\
\hline Mean & 66.6 & $67.3^{\mathrm{a}}$ & 66.4 & $65.6^{\mathrm{b}}$ & 67.3 & 17.1 & 16.5 & $15.3^{b}$ & $13.5^{\mathrm{b}}$ & $14.7^{\mathrm{c}}$ & 49.5 & $50.8^{c}$ & $51.1^{\mathrm{c}}$ & $52.2^{c}$ & $52.5^{c}$ \\
\hline SD & 6.9 & 6.7 & 6.6 & 6.7 & 7.2 & 3.9 & 3.3 & 3.6 & 3.6 & 4.2 & 7.3 & 7.6 & 8.2 & 7.6 & 7.4 \\
\hline
\end{tabular}

${ }^{\mathrm{a}} P<0.05 ;{ }^{\mathrm{b}} P<0.01 ;{ }^{\mathrm{c}} P<0.001$ difference with pre-training $(0)$ value (Wilcoxon signed-rank) 
Table 3. Sleeping metabolic rate and respiratory exchange ratio before (0) and $8,20,40$, and 90 weeks after the start of the training period

\begin{tabular}{|c|c|c|c|c|c|c|c|c|c|}
\hline \multirow[t]{2}{*}{ Weeks } & \multicolumn{4}{|c|}{$\begin{array}{l}\text { Sleeping metabolic } \\
\text { rate }\left(\mathrm{MJ} \cdot \text { day }^{-1}\right)\end{array}$} & \multicolumn{5}{|c|}{$\begin{array}{l}\text { Respiratory exchange } \\
\text { ratio }\end{array}$} \\
\hline & 0 & 20 & 40 & 90 & 0 & 8 & 20 & 40 & 90 \\
\hline
\end{tabular}

Women $(n=11)$

\begin{tabular}{lllllllllll} 
Mean & 6.0 & 6.2 & 6.0 & 5.8 & 5.8 & 0.78 & 0.79 & 0.80 & $0.85^{\mathrm{b}}$ & $0.81^{\mathrm{b}}$ \\
SD & 0.5 & 0.4 & 0.4 & 0.3 & 0.3 & 0.02 & 0.03 & 0.04 & 0.03 & 0.02 \\
Men $(n=12)$ & & & & & & & & & \\
Mean & 6.9 & 6.9 & 7.0 & $6.6^{\mathrm{a}}$ & 6.8 & 0.79 & 0.80 & $0.83^{\mathrm{a}}$ & $0.85^{\mathrm{b}}$ & $0.83^{\mathrm{b}}$ \\
SD & 0.5 & 0.5 & 0.7 & 0.6 & 0.4 & 0.03 & 0.03 & 0.06 & 0.04 & 0.03 \\
Total $(n=23)$ & & & & & & & & & \\
Mean & 6.5 & 6.6 & 6.5 & $6.2^{\mathrm{b}}$ & 6.3 & 0.79 & 0.79 & $0.82^{\mathrm{a}}$ & $0.85^{\mathrm{c}}$ & $0.82^{\mathrm{c}}$ \\
SD & 0.7 & 0.6 & 0.7 & 0.6 & 0.6 & 0.03 & 0.03 & 0.05 & 0.04 & 0.03 \\
\hline
\end{tabular}

${ }^{\mathrm{a}} P<0.05 ;{ }^{\mathrm{b}} P<0.01 ;{ }^{c} P<0.001$ difference with pre-training $(0)$ value (Wilcoxon signed-rank)

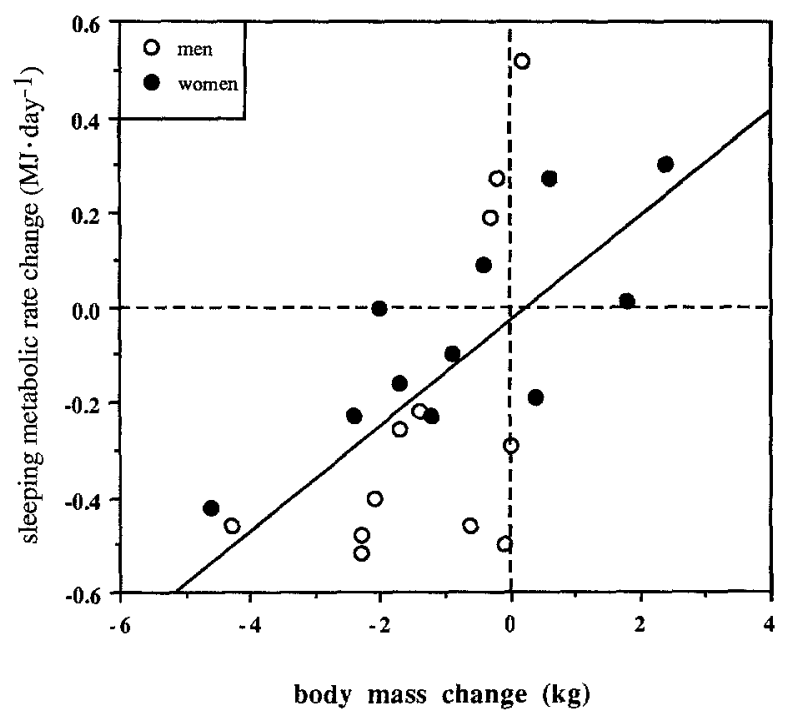

Fig. 1. The change in sleeping metabolic rate plotted as a function of the change in body mass from before to 40 weeks after training with the calculated linear regression line $(r=0.62, P=0.001)$

The SMR showed a tendency to decrease (Table 3). At the end of the training programme, the mean value had dropped from 6.5 (SD 0.6) $\mathrm{MJ} \cdot$ day $^{-1}$ to 6.2 (SD $0.6) \mathrm{MJ} \cdot$ day $^{-1}[F(1,3)=4.3, P<0.01]$. There was no interaction between the sexes $[F(3,19)=1.9, P=0.12]$. The decrease in SMR was not maintained after the training programme. Overnight substrate utilization showed a change to relatively less fat and more carbohydrate oxidation, as indicated by the increased $R$ (Table $3, P<0.001$ ).

Changes in SMR were related to changes in BM. The loss in BM at the end of the training period was significantly related to the decrease in SMR (Fig. 1; Pearson $r=0.62, P=0.001)$. The decrease of BM explained $38 \%$ of the variance in the decrease in SMR. In a multiple regression analysis with the change in
SMR as the dependent variable and the change in FFM and the change in FM as the independent variables, the variation explained was equally large (Pearson $r=0.62, P<0.01$ ). Changes in FM and FFM affected SMR at an equal rate.

\section{Discussion}

The exercise training in the present study induced an increase in average daily metabolic rate of 22 (SD 10) $\%$. The subjects started at a level of light physical activity [(average daily metabolic rate) $\cdot \mathrm{SMR}^{-1}$ ] and increased the physical activity level to values for moderate to high activity (World Health Organisation 1985). Assuming that diet induced thermogenesis was $10 \%$ of average daily metabolic rate, activity induced energy expenditure was calculated as $\{[0.9 \cdot$ (average daily metabolic rate)]-SMR\}. Activity induced energy expenditure increased from 30 (SD 6) \% to 42 (SD 4) $\%$ of average daily metabolic rate. In reality, the increase was slightly higher as the subjects were in a negative energy balance losing fat. However, the correction is negligible as, for example, a loss of $4 \mathrm{~kg}$ fat over 40 weeks is equivalent to $0.5 \mathrm{MJ} \cdot \mathrm{day}^{-1}$ with a corresponding diet induced thermogenesis of less than $1 \%$ of the daily energy turnover in a subject expending 12 MJ $\cdot$ day $^{-1}$. Apart from this the subjects gained FFM, which partly compensated for the lost energy.

The most pronounced effect of the exercise training was on FFM. At the first observation, 8 weeks after the start of the training programme, the increase of FFM was already significant with an overall mean increase of $1.3 \mathrm{~kg}(P<0.001)$. During the remaining 32 weeks of the training programme FFM increased further by $1.4 \mathrm{~kg}$ on average. The increase was maintained during the year after the programme. The increase in FFM is most probably an increase in muscle mass. Results from measurements of total body water by isotope dilution in 13 of the 23 subjects supported this conclusion (Westerterp et al. 1992a).

Surprisingly, training induced an overnight increase in $R$. One would have expected a decrease in $R$ given the loss of body fat. The explanation for this observation could be threefold. Firstly, the well-known exercise induced lipid utilization (Bielinski et al. 1985; Tremblay et al. 1992) was restricted to daytime, thereby saving glucose for storage as glycogen to be utilized overnight, during the postabsorptive period. Secondly, training could have induced an increase in the glycogen stores, probably through an increase in insulin sensitivity (Meredith et al. 1989). Thirdly, it could have been a consequence of a change in the food quotient of the diet. However, dietary changes were not observed (Westerterp et al. 1992a) but cannot be excluded as there was a significant underreporting of dietary intake of -19 (SD 17) \% in the observation interval after 40 weeks (Westerterp et al. 1992b). In an earlier study on the effects of a 12 months' training programme, Janssen and ten Hoor (1989) have shown significant change towards higher food quotient values. 
The SMR did not change in parallel to the FFM changes as expected. There was absolutely no indication of an increase in SMR. In fact, the opposite was visible. Firstly, at the highest training intensity, 40 weeks after the start of the programme, SMR was slightly lower $(P<0.05)$ while FFM had increased on average by $5 \%(P<0.001)$. Secondly, 1 year after the training programme FFM was still at the same increased level but SMR was on average not significantly different from the pretraining value. The latter is also an indication of the fact that the observed decrease in SMR cannot be explained by adaptation to the respiration chamber.

The observed relationship between the change in SMR and BM can be explained as a defence mechanism in the maintenance of $\mathrm{BM}$. The training induced an increase in average daily metabolic rate of 22 (SD $10) \%$. There was no indication of an increase in energy intake (EI) as measured using a 7-day dietary record (Westerterp et al. 1992a). The discrepancy between average daily metabolic rate and EI is probably mainly due to underreporting of EI (Westerterp et al. 1992b). However, the subjects finally lost on average 1-kg BM and the change in BM explained a significant part of the variance in the change in SMR. The higher the loss of BM the larger the decrease in SMR.

One explanation for the apparent contradiction in our results, that RMR did not change in parallel with the FFM changes, is perhaps in the method used for measuring RMR, i.e. during sleep (SMR). Bielinski et al. (1985) have reported no change in SMR while RMR was increased in the early morning after a day with 3-h exercise. Bingham et al. (1989) have measured subjects over a 9-week training programme with an exercise intensity comparable to that in the present study and found no change in SMR. In the present study, we did not find significant changes in SMR until training had reached its maximal intensity after 40 weeks. One of the suggested mechanisms for the mentioned training induced increase in RMR is a higher substrate flux. The results of the present study would suggest that such an increase does not affect SMR.

Cross-sectional studies, comparing SMR values of endurance athletes with control subjects, have not revealed metabolic adaptations in a direction of lower energy requirements (Schulz et al. 1991, 1992). In the present longitudinal study, average daily metabolic rate (ADMR) showed an initial increase of on average more than $20 \%$ and remained stable from the 8 th to the 40th week of the training programme although the amount of training doubled over this period (Westerterp and Saris 1991; Westerterp et al. 1992a). One explanation for the lack of an increase after the 8th week is a decrease of other components of ADMR during the course of the training programme. The initial increase of ADMR was nearly three times the calculated cost of running, possibly explained by an increase in habitual activity and diet-induced thermogenesis (Meijer et al. 1991a). After 40 weeks the total increase of ADMR matched the calculated energy cost for running. Finally, the decrease in SMR by the 40th week had contributed to the maintenance of energy balance: an explanation which is supported by the observed relationship between the change in SMR and BM as mentioned earlier. Phinney et al. (1988) have reported a comparable decrease of RMR in subjects combining a severe weight reducing diet with supervised endurance exercise. In this situation of a strongly negative energy balance, the decrease of RMR had already occurred after 4 weeks of training. Similarly, Tremblay et al. (1990) have found a tendency for a decrease of RMR after a 100-day exercise training programme in moderately overweight men accompanied by a significant reduction in body mass, mainly by fat loss.

The decrease in SMR was not maintained after the training programme, either in the subjects who ceased training, or in those who continued training. However, we must take into account that the total group of 23 subject fell into three subgroups, i.e. 4 subjects who continued training at the same intensity, 7 who continued training at a reduced intensity and 12 who ceased training. Thus, the numbers are too small to draw definite conclusions at this point.

In conclusion, it would seem from our study that an exercise induced increase in FFM does not result in an increase in SMR. There was an indication of the opposite effect, a decrease in SMR in the long term during training, possibly as a defense mechanism of the body in the maintenance of BM.

\section{References}

Bielinski R, Schutz Y, Jéquier E (1985) Energy metabolism during the postexercise recovery in man. Am J Clin Nutr 42:6982

Bingham SA, Goldberg GR, Coward WA, Prentice AM, Cummings JH (1989) The effect of exercise and improved physical fitness on basal metabolic rate. Br J Nutr 61:155-173

Bogardus C, Lillioja S, Ravussin E, Abbott W, Zawadzki JK, Young A, Knowler R, Jacobowitz WC, Moll PP (1986) Familial dependence of the resting metabolic rate. $\mathrm{N}$ Engl $\mathrm{J}$ Med 315:96-100

Gaesser GA, Brooks GA (1984) Metabolic bases of post-exercise oxygen consumption: a review. Med Sci Sports Exerc 16:2943

Garby L, Garrow JS, Jørgensen B, Lammert O, Madsen K, S $\emptyset$ rensen P, Webster J (1988) Relation between energy expenditure and body composition in man: specific energy expenditure in vivo of fat and fat-free tissue. Eur J Clin Nutr 42:301306

Goran MI, Poehlman ET (1992) Endurance training does not enhance total energy expenditure in healthy elderly persons. Am J Physiol 263:E950-E957

Horton ES (1985) Metabolic aspects of exercise and weight reduction. Med Sci Sports Exerc 18:10-18

Janssen GME, ten Hoor F (1989) Marathon running: functional changes in male and female subjects during training and contests. Int J Sports Med 10:s118-s123

Meijer GAL, Janssen GME, Westerterp KR, Verhoeven F, Saris WHM, ten Hoor F (1991a) The effect of a 5-month endurance-training programme on physical activity: evidence for a sex difference in the metabolic response to exercise. Eur J Appl Physiol 62:11-17

Meijer GAL, Westerterp KR, Seyts GHP, Janssen GME, Saris WHM, ten Hoor F (1991b) Body composition and sleeping 
metabolic rate in response to a 5-month endurance-training programme in adults. Eur J Appl Physiol 62:18-21

Meredith CN, Frontera WR, Fisher EC, Hughus VA, Herland JC, Edwards J, Evans WJ (1989) Peripheral effects of endurance training in young and old subjects. J Appl Physiol $66: 2844-2849$

Phinney SD, LaGrange BM, O'Connell M, Danforth Jr E (1988) Effects or aerobic exercise on energy expenditure and nitrogen balance during very low calorie dieting. Metabolism 37:758-765

Poehlman ET, Horton ES (1989) The impact of food intake and exercise on energy expenditure. Nutr Rev 47:129-137

Poehlman ET, Melby CL, Badylak SF, Calles J (1989) Aerobic fitness and resting energy expenditure in young adult males. Metabolism 38:85-90

Poehlman ET, Melby CL, Goran MI (1991) The impact of exercise and diet restriction on daily energy expenditure. Sports Med 11:78-101

Saris WHM (1991) Exercise, nutrition and weight control. In: Brouns F, Saris WHM, Newsholme EA (eds) Advances in nutrition and topsport. Karger Med Sport Sci Ser 32:200-216

Schoffelen PFM, Saris WHM, Westerterp KR, ten Hoor F (1984) Evaluation of an automated indirect calorimeter for measurement of energy balance in man. In: van Es AJH (ed) Human energy metabolism: physical activity and energy expenditure measurements in epidemiological research based upon direct and indirect calorimetry. Euro-Nut report no. 5, pp 51-54, Stichting Nederlands Instituut voor de Voeding, Wageningen, The Netherlands

Schulz LO, Nyomba BL, Alger S, Anderson TE, Ravussin E (1991) Effect of endurance training on sedentary energy expenditure in a respiration chamber. Am J Physiol 260:E257E261

Schulz LO, Alger S, Harper I, Wilmore JH, Ravussin E (1992) Energy expenditure of elite female runners measured by respiratory chamber and doubly labeled water. J Appl Physiol $72: 23-28$
Schutz Y, Bessard T, Jéquier E (1984) Diet-induced thermogenesis measured over a whole day in obese and nonobese women. Am J Clin Nutr 40:542-552

Siri WE (1956) Advances in biological and medical physics. Academic Press, New York, pp 239-280

Tremblay A, Fontaine E, Nadeau A (1985) Contribution of postexercise increment in glucose storage to variations in glucoseinduced thermogenesis in endurance athletes. Can J Physiol Pharmacol 63:1165-1169

Tremblay A, Fontaine E, Poehlman ET, Mitchell D, Perron L, Bouchard C (1986) The effect of exercise-training on resting metabolic rate in lean and moderately obese individuals. Int $\mathbf{J}$ Obes 10:511-517

Tremblay A, Nadeau A, Desprès J-P, St-Jean L, Thériault G, Bouchard C (1990) Long-term exercise training with constant energy intake. 2. Effect on glucose metabolism and resting energy expenditure. Int J Obes 14:75-84

Tremblay A, Coveney S, Després J-P, Nadeau A, Prud'homme D (1992) Increased resting metabolic rate and lipid oxidation in exercise-trained individuals: evidence for a role of $\beta$-adrenergic stimulation. Can J Physiol Pharmacol 70:1342-1347

Westerterp KR, Saris WHM (1991) Limits of energy turnover in relation to physical performance, achievement of energy balance on a daily basis. J Sports Sci 9:1-15

Westerterp KR, Meijer GAL, Janssen EME, Saris WHM, ten Hoor F (1992a) Long-term effect of physical activity on energy balance and body composition. Br J Nutr 68:21-30

Westerterp KR, Verboeket-van de Venne WPHG, Meijer GAL, ten Hoor F (1992b) Self-reported intake as a measure for energy intake, a validation against doubly labeled water. In: Ailhaud g, Guy-Grand B, Lafontan M, Ricquier D (eds) Obesity in Europe 91. Libbey, London, pp 17-22

World Health Organization (1985) Energy and protein requirements. Report of a joint FAO/WHO/UNU Expert Consultation. Technical Report Series no. 724. WHO, Geneva 